\title{
Surrogate Humanity: Resistant Art Practices under Technoliberalism
}

\author{
STEPHANIE KANG \\ $\mathrm{PhD}$ Candidate, The Ohio State University
}

\begin{abstract}
This essay reviews the book Surrogate Humanity: Race, Robots, and the Politics of Technological Futures, co-written by Neda Atanasoski and Kalindi Vora. In this critical text, Atanasoski and Vora consider the ways in which liberal structures of anti-Blackness, settler colonialism, and capitalist exploitation have been ingrained into robotic technologies. By revealing the interwoven relationship between technological development and racial dispossession, Surrogate Humanity searches for alternative models of human-machine interactions that can destabilize social inequalities and their reproductions.
\end{abstract}

With ongoing advancements in the fields of artificial intelligence and robotic technologies, technoliberalism has purported to liberate humans from mundane, degrading forms of labor, a condition that Neda Atanasoski and Kalindi Vora describe as the surrogate human effect. However, in their book Surrogate Humanity: Race, Robots, and the Politics of Technological Futures, the authors contend that within the logics of capitalism, the liberal subject can exist only through the exploitation and dispossession of its racialized, gendered, and colonized counterparts, who are dehumanized through their invisible labor. Therefore, this book argues, technoliberalism, which is defined by the authors as "the political alibi of present-day racial capitalism that posits humanity as an aspirational figuration in a relation to technological transformation,"1 is contingent on the same systems of anti-Blackness, settler colonialism, and patriarchy that regulate the capitalist productions that decide what separates the worker from the non-worker, the human from the nonhuman. Essentially, as the authors emphasize in their book, the subject can only be free through the surrogate's unfreedom.

Building on work by scholars such as Ruha Benjamin and Wendy Hui Kyong Chun, Atanasoski and Vora work to unhinge the fantasy of post-racial neutrality, which is carried out by technologies that maintain a narrative of universal humanity while actually upholding the racialized order of things. As they state, "Technoliberalism embraces the 'post'-racial logic of racial liberalism and its conception of historical, economic, and social newness, limiting the engineering, cultural, and political imaginaries of what a more just and equal future looks like within technological modernity." 2 Through a series of case studies that are introduced over a span of six chapters, they demonstrate just how much hierarchical systems of power are ingrained in our technologies. In addition to offering an impressive historical analysis of robotic technologies from the twentieth 
century to the present, Atanasoski and Vora challenge projected technoliberal futures that limit the possibility of engineering imaginaries. Their book Surrogate Humanity demonstrates the ways in which the surrogate effect has played into the propagation of technoliberalism, while also offering alternative methods for interrupting technoliberalist motives.

Chapter 1 begins with a survey of automation practices, which the authors argue are equally grounded within liberal-capitalism and totalitarian-fascism. While the former claims to free the worker for more creative tasks, the latter tries to suppress the worker's ability to rebel. As Atanasoski and Vora contend, these two ideologies are not fundamentally opposed as one might be led to believe, but are deeply codependent in their technoliberal pursuits. Chapter 2 examines what the authors call the "fourth industrial revolution," a time period in which machines developed an ability to produce and program themselves. This "second machine age," while claiming to produce democratic platforms for users through shared economies and collaborative robotics, only obfuscates the racial inequities that continue to be accelerated by new technologies. Chapter 3 analyzes the harmful erasure of marginalized workers, who are made invisible through digital platforms that disguise human labor as machine labor. Looking to examples like Amazon's warehouse model or Mechanical Turk, the labor of dispossessed workers remains out of sight and thus unprotected. Chapter 4 turns to robots that are used to serve emotional and therapeutic needs for humans. Through their obedience and subservience to humans, sociable robots reflect the imperial and racial logics that are used to distinguish the human from the non-human, the master from the servant. Chapter 5 considers robots that are used for warfare, such as unmanned drones, which are perceived as autonomous but are still operated and controlled by humans. Chapter 6 builds upon this concept by considering the possibility for artificial intelligence to have empathy. While debates around killer robots have centered on the machine's inability to feel empathy for its targets, the writers argue that the emphasis on empathy within conversations about human rights reify the human as the primary liberal subject.

Despite the bleak reality that is laid out through the book's six chapters, Atanasoski and Vora still find glimmers of hope for alternative methods of resistance, in which robotic technologies can disrupt racial, gendered, and colonial systems of inequality. They point specifically to this potential through examples of contemporary art practices that utilize technological platforms to destabilize their embedded social hierarchies from within. Kelly Dobson, an artist and engineer, created Omo, a therapy robot (or carebot) that unsettles the idea that human-robot relations must be predicated on the robot's productivity, functionality, and subservience. Artist Addie Wagenknecht uses drones to paint, a creative activist strategy that challenges the technology's intended use while also appropriating its built-in errors. Similarly, the Italian artist group IOCOSE disrupts the purpose of killer robots, which are seemingly autonomous in their targeted acts, by creating drone selfies that imagine an alternative present and future where technological warfare is no longer a reality. Through these examples, Atanasoski and Vora ask, how can art and technology be used to imagine new possibilities for human and robot connections? How can engineering and robotic technologies be creatively implemented to destabilize a surrogate human effect that perpetuates social hierarchies and inequities?

The authors of Surrogate Humanity present an ambitious project that contends with some of the most difficult questions facing new technologies and their related labor practices. Atanasoski and Vora orient their insightful analyses through an intersectional lens that is refreshing and much needed within the technosciences. However, while this book attempts to include a vast survey, covering topics that examine the automation, collaboration, domestication, personification, and 
weaponization of robotic technologies, its technology-focused approach perhaps misses an opportunity to return the conversation to the heart of the problem: the humans behind this laborthe engineers who continue to program their racial and gender biases into their machines and the marginalized workers who remain invisible through their persisting exploitation and displacement. Readers of Surrogate Humanity would perhaps benefit by accompanying their analysis of this text with the work of Black scholars like Safiya Umoja Noble and Simone Browne, who more pointedly examine the effects that racialized technologies have on their users, and specifically, their Black users. ${ }^{3}$ While these questions are addressed to a degree within Surrogate Humanity, I can't help but wonder, how can the relationship between humans and technologies be discussed in a more symbiotic fashion? By integrating the work of Black scholars and artists more intentionally into the book's discussion of racial capitalism, Surrogate Humanity would have been able to bridge the dichotomy between humans and machines more effectively, allowing the book's argument to more fully and satisfyingly tackle the racial implications and effects of these technologies on their human counterparts.

Nevertheless, Neda Atanasoski and Kalindi Vora provide an important and insightful perspective on the technologies that are used to maintain social structures of racial capitalism. Their book is quite timely in a post-Trump era, in which a narrative of white loss has been used and exploited for imperialistic purposes. As automation has become increasingly prevalent at all levels of the workforce, the technoliberalist fear that human labor, and specifically white labor, is being expropriated by machines ironically overlooks the racist discourse that is used to habitually erase marginalized workers from the conversation. Ultimately, whose labor is replaceable and expendable? By taking on a feminist and anti-colonial approach, their book serves as a meaningful reminder that scholars and engineers must continue to reassess and unsettle the inherent biases that exist within their fields. Overall, Surrogate Humanity is essential reading for those invested in topics of robotic engineering, artificial intelligence, labor politics, critical race theory, and their intersections.

\section{ENDNOTES}

${ }^{1}$ Neda Atanasoski and Kalindi Vora, Surrogate Humanity: Race, Robots, and the Politics of Technological Futures (Durham: Duke University Press, 2019), 4.

2 Ibid., 14.

${ }^{3}$ Safiya Umoja Noble, Algorithms of Oppression: How Search Engines Reinforce Racism (New York: New York University Press, 2018); Simone Brown, Dark Matters: On the Surveillance of Blackness (Durham: Duke University Press, 2015).

\section{REFERENCES}

Neda Atanasoski and Kalindi Vora, Surrogate Humanity: Race, Robots, and the Politics of Technological Futures (Durham: Duke University Press, 2019).

Ruha Benjamin, Race After Technology: Abolitionist Tools for the New Jim Code (Cambridge: Polity Press, 2019).

Safiya Umoja Noble, Algorithms of Oppression: How Search Engines Reinforce Racism (New York: New York University Press, 2018). 
Simone Brown, Dark Matters: On the Surveillance of Blackness (Durham: Duke University Press, 2015).

Wendy Hui Kyong Chun, Control and Freedom: Power and Paranoia in the Age of Fiber Optics (Cambridge: MIT Press, 2006).

\section{AUTHOR BIO}

Stephanie Kang specializes in contemporary art history with a focus on new media art and theory. She received an MFA in Visual Art from Washington University in St. Louis and is currently a $\mathrm{PhD}$ candidate in the History of Art at the Ohio State University. She has had interviews and essays published by Flash Art Online, the Wexner Center for the Arts, and Front International: Cleveland Triennial for Contemporary Art. Most recently, she was hired as the assistant curator at the Contemporary Arts Center in Cincinnati, Ohio. 